\title{
The Effect of Hyaluronidase in Interlaminar Lumbar Epidural Injection for Failed Back Surgery Syndrome
}

\author{
Sang Beom Kim, M.D., Kyeong Woo Lee, M.D., Jong Hwa Lee, M.D., \\ Min Ah Kim, M.D., Byoung Woo An, M.D.
}

Department of Physical Medicine and Rehabilitation, Dong-A University College of Medicine, Busan 602-715, Korea

Objective To evaluate the effect of hyaluronidase in patients with failed back surgery syndrome (FBSS) treated with interlaminar lumbar epidural injection (ILEI).

Method Sixty patients suffering from severe low back pain and sciatica were randomly allocated into three groups. Group T received ILEI with $2 \mathrm{ml}$ triamcinolone $40 \mathrm{mg} / \mathrm{ml}$ and $5 \mathrm{ml}$ bupivacaine $0.25 \%$. Group H received ILEI with $1500 \mathrm{IU}$ hyaluronidase and $5 \mathrm{ml}$ bupivacaine $0.25 \%$. Group TH received interlaminar lumbar epidural injection (ILEI) with $1500 \mathrm{IU}$ hyaluronidase, $2 \mathrm{ml}$ triamcinolone $40 \mathrm{mg} / \mathrm{ml}$ and $5 \mathrm{ml}$ bupivacaine $0.25 \%$. The effect was evaluated using Visual Analogue Scale (VAS) and Oswestry Disability Index (ODI) at pre-injection, 2 weeks, 6 weeks and 12 weeks after ILEI.

Results After 2 weeks and after 6 weeks, patients in both Group T and Group TH had significant effectiveness more than Group H in decrease of VAS and ODI. After 12 weeks, only patients in Group TH had significant effectiveness in decrease of VAS and ODI $(\mathrm{p}<0.05)$. In every period, Group TH had the most effectivess in decrease of VAS and ODI after ILEI.

Conclusion ILEI for FBSS with triamcinolone and hyaluronidase is considered to have more long term effectiveness to reduce pain and improve function after ILEI than injection with triamcinolone alone or hyaluronidase alone.

Key Words Failed back surgery syndrome, Interlaminar lumbar epidural injection, Hyaluronidase

Received March 19, 2012; Accepted May 15, 2012

Corresponding author: Byoung Woo An

Department of Physical Medicine and Rehabilitation, Dong-A University College of Medicine, 65, Mangyang-ro, 111 beon-gil, Seo-gu, Busan 602715, Korea

Tel: +82-51-240-5690, Fax: +82-51-254-8511, E-mail: idbargab@daum.net (ㄷ) This is an open-access article distributed under the terms of the Creative Commons Attribution Non-Commercial License (http:// creativecommons.org/licenses/by-nc/3.0) which permits unrestricted noncommercial use, distribution, and reproduction in any medium, provided the original work is properly cited.

Copyright $\odot 2012$ by Korean Academy of Rehabilitation Medicine

\section{INTRODUCTION}

Chronic low back pain refers to pain in the lower back that persists 12 months after the initial symptoms were exhibited. It has a $75 \%$ morbidity rate. ${ }^{1}$ A common treatment for this condition is surgery. In fact, the USA had spent 2.5 billion dollars on lower back surgeries alone. ${ }^{2}$ However, even after surgical treatments for lower back pain, lower extremity pain or neurologic symptoms would remain. These cases are defined as Failed Back 
Surgery Syndromes (FBSS). ${ }^{3}$ FBSS occur in $5-40 \%$ of patients that underwent a back surgery ${ }^{2}$ due to spinal stenosis, spinal segment degeneration, disc ruptures, recurred disc herniation, disc fragments remained after surgery, epidural scars, facet joint pain, sacroiliac joint pain, spinal segment instability, etc. ${ }^{4}$ The most common cause of FBSS is an epidural scar. ${ }^{5}$ Fibroplasia findings can generally be observed around nerve roots in magnetic resonance imaging or epidurography. ${ }^{6}$ Fibroplasia occurs due to the fibrin created from the chronic inflammatory process that occurs following surgery and is deposited about the nerve root causing damage to the nerve root and restricting blood circulation. Fibroplasia suppresses the mobility of nerve roots. So certain motions trigger pain by stretching nerve root. ${ }^{7,8}$ Extremely fibroplasias limits the diffusion of drugs, thereby reducing the efficacy of drugs injected for treatment. ${ }^{9}$

In this respect, this study intended to implement the epidural steroid injection as a treatment of low back pain and lower extremity radiating pain related with spinal lesion on FBSS. To reduce fibroplasias and to remove barriers between tissues, unlike conventional epidural steroid injection, we added hyaluronidase ${ }^{10}$ that hydrolyzes glucosaminic bonds between hyaluronic acid which is a major intercellular substance and connective tissues.

Among related previous studies, a Korean study reported that adding hyaluronidase on the nerve root blocks showed significant effects on FBSS patients. ${ }^{11}$ Among other international studies, one study reported that the rebound radicular pain due to post-laminectomy scarring in the intervertebral foramens and epidural spaces in a 31-year old male patient were reduced by repeated hyaluronidase injections around the scars. ${ }^{12}$ Another study reported that hyaluronidase and methylprednisolone nerve root blocks were performed on 20 FBSS patients and continuous pain relieving effects were observed in 11 out of the 20 patients for at least three months. ${ }^{13}$ However, these studies had limitations such as: no control group, a small numbers of subjects or a failure to control elements that might affect treatment effects such as combination treatments following the procedure. The purpose of this study was to conduct randomized controlled trials on 60 FBSS patients in order to ascertain the usefulness of hyaluronidase in relieving pain. Many of the subjects had undergone a total radical laminectomy or a posterior lateral lumbar fixation (following a total radical laminectomy for instability prevention) it was believe that surgery may have affected tissues at the surgical in a wider area than in patients that had undergone a partial laminectomy. Therefore, this study was conducted under the judgment that interlaminar ligament approaches would be more suitable for the subjects than selective nerve root blockades through intervertebral foramens.

\section{MATERIALS AND METHODS}

\section{Subjects}

This study was conducted on those failed back surgery syndrome patients that visited the rehabilitation medicine department of Dong-A University Hospital between January and October 2010 because of low back pain or lower extremity radiating pain that recurred after a spinal surgery.

Among the significant findings that might trigger FBSS, this study included patients that showed magnetic resonance imaging findings of fibroplasias around nerve roots, ${ }^{11}$ central spinal canal stenosis, lateral recess stenosis, intervertebral foramen stenosis, recurrent herniation of intervertebral disc or disc fragments remaining after surgery. The patient exclusion criteria were those with spondylolisthesis, an instability or fractures of the spine uncovered in a simple lumbar radiography that was conducted with the patient in dynamic forward flexionextension and lateral flexion postures. Other patient exclusion criteria were those that had facet joint lesions or sacroilitis revealed through magnetic resonance imaging, that was not treatable by epidural injection. In addition, among the study subjects, those that had undergone surgeries two or more times were excluded.

In this study, the procedures were explained to all the patients and written consents were received from the patients. Patients with hemostatic disorders, infection, systemic steroid use or hyaluronidase had been contraindicated were excluded from this study.

\section{Methods}

The 60 patients were randomly divided into three groups: T, H, TH based on the different drugs and ILEI that were conducted. Each group received different treatments. Group T received triamcinolone and bupivacaine, group $\mathrm{H}$ received hyalurondiase and bupivacaine and group TH received triamcinolone, bupivacaine and hyalurondiase. The groups were compared for the degrees of pain relief and length of time during with the pain 
relief was maintained. ILEI was conducted when each patient was in a lateral recumbent position while his/her neck, pelvis and knees were bent. The skin and subcutaneous tissues were anesthetized by injecting 1-2 $\mathrm{ml}$ of lidocaine between L4 and L5 spinous processes and a 20 gage Touhy needle was inserted approximately $2-3 \mathrm{~cm}$ so that the needle went into the interspinal ligament. Then, a syringe containing air was attached to the needle and the needle was inserted slowly, 1-2 $\mathrm{mm}$ at a time until no resistance was felt. Afterward, $2 \mathrm{ml}$ of nonionic radiocontrast was injected into the location of the needle to identify that the contrast was diffusing in the shape of thin strings toward the top of the image.

When the needle was identified in the epidural space through the interspinal ligament approach method, $2 \mathrm{ml}$ triamcinolone $40 \mathrm{mg} / \mathrm{ml}$ and $5 \mathrm{ml}$ bupivacaine $0.25 \%$, were injected if the patient was in group $\mathrm{T}(\mathrm{n}=20)$ and 1500 IU hyaluronidase and $5 \mathrm{ml}$ bupivacaine $0.25 \%$ were injected if the patient was in group $\mathrm{H}(\mathrm{n}=22)$. If the patient was in group TH ( $\mathrm{n}=23)$, a mixture of $1500 \mathrm{IU}$ hyaluronidase, $2 \mathrm{ml}$ triamcinolone $40 \mathrm{mg} / \mathrm{ml}$ and $5 \mathrm{ml}$ bupivacaine $0.25 \%$ was injected.

The effects of the procedures were evaluated by measuring the Visual Analogue Scale (VAS) and Oswestry Disability Index (ODI) before the procedures and two weeks, six weeks and 12 weeks after the procedure.

To control elements that might affect treatment effects, the patients that participated in the study were prescribed oral medicines containing the same material as their designated group for two weeks and no physical therapy was implemented.

\section{Statistics}

The SPSS 14.0 statistical program for Windows was used for all analysis. Repeated measures ANOVA and ANOVA were used for statistical analysis of changes in VAS and ODI of the three groups between before the procedures and 2, 6, and 12 weeks after the procedures. Post-hoc tests were conducted using the Tukey-Kramer method and cases where the p-value was 0.05 or smaller were considered as being statistically significant.

\section{RESULTS}

The number of study participants that visited the rehabilitation medicine department of Dong-A University Hospital, were diagnosed with FBSS and participated in this study between January and October 2010 was 65 consisting of 20 in group T, 22 in group $\mathrm{H}$ and 23 in group TH. Sixty patients: consisting of 20 in group T, 17 in group $\mathrm{H}$

Table 1. General Characteristics of Patients

\begin{tabular}{|lccc}
\hline & T (n=20) & H (n=17) & TH (n=23) \\
\hline Age (years) & $63.6 \pm 9.8$ & $61 \pm 8.5$ & $62 \pm 11.6$ \\
\hline Sex (male/female) & $9 / 11$ & $6 / 11$ & $12 / 11$ \\
\hline Weight (kg) & $62.6 \pm 10.2$ & $61.2 \pm 11.4$ & $61.3 \pm 10.8$ \\
\hline Height (cm) & $160.3 \pm 8.2$ & $161.7 \pm 7.9$ & $161.1 \pm 9.8$ \\
\hline Time from operation to OPD visit (months) & 49.7 & 49 & 49.5 \\
\hline Operation type & & & \\
\hline TL & $2 / 20(10.0 \%)$ & $2 / 17(11.8 \%)$ & $4 / 23(17.4 \%)$ \\
\hline TLF & $9 / 20(45.0 \%)$ & $6 / 17(35.3 \%)$ & $8 / 23(34.8 \%)$ \\
\hline PL & $9 / 20(45.0 \%)$ & $9 / 17(52.9 \%)$ & $11 / 23(47.8 \%)$ \\
\hline Level of operation & & & 2 \\
\hline L2-L3 & 0 & 0 & 2 \\
\hline L3-L4 & 5 & 4 & 17 \\
\hline L4-L5 & 15 & 13 & 5 \\
\hline L5-S1 & 5 & 3 & \\
\hline
\end{tabular}

Values are mean \pm standard deviation

T: Triamcinolone and bupivacaine group, H: Hyaluronidase, bupivacaine group, TH: Triamcinolone, hyaluronidase, bupivacaine group, OPD: Out-patient department, TL: Total laminectomy, TLF: Total laminectomy, posterolateral lumbar fixation, PL: Partial laminectomy 
and 23 in group TH could participate in a follow up until 12 weeks after the procedures. Except for the gender ratio between males/females, there were no significant differences in age, weights and time from the operation to the out-patient department visit among the three groups. Among their surgical methods, a partial laminectomy was the most common followed by a combination of a total radical laminectomy and a posterior lateral lumbar fixation and a simple total radical laminectomy in the order of precedence. Among their surgical levels, L4-5 was the most common level (Table 1).

No significant differences were observed among the three groups in preoperative VAS and ODI ( $p>0.05)$. Based on the comparison of average values, in the group $\mathrm{T}$, the average VAS value significantly decreased for two weeks after the procedure and was maintained thereafter without any further decrease. The average ODI value in the group $\mathrm{T}$ decreased after the procedure and then the average ODI increased for six weeks after the procedure. Finally the average ODI value had no statistically significant difference from the value before the procedure by 12 weeks after the procedure. In the group $\mathrm{TH}$, the average VAS and ODI values statistically significantly decreased for two weeks and showed no significant change thereafter until six weeks following the procedure but showed findings of continuous decreases even 12 weeks after the procedure unlike group $\mathrm{T}$. In the group $\mathrm{H}$, no significant changes were shown in the average values in any cases of measurement after the procedure (Table 2).

Table 3 shows decreases in VAS and ODI values at 2, 6, and 12 weeks after the procedure in comparison with the values before the procedure respectively. Based on a review of decrements in VAS and ODI values, in the group T, VAS showed a constant decrement at all times and ODI showed significantly decreasing decrements between 6 weeks and 12 weeks after the procedure. In the group $\mathrm{TH}$, both VAS and ODI showed findings of increasing decrements 12 weeks after the procedure when a considerable time passed after the procedure. In the group $\mathrm{H}$, the values did not show any significant changes in decrements. When decrements in the three groups were compared between the time points, group TH showed larger decrements than group $\mathrm{T}$ in measured values of both VAS and ODI based on 12 weeks after the procedure in particular (Table 3).

To check whether hyaluronidase was effective in re-

Table 2. Comparison of Mean VAS and ODI in Each Group

\begin{tabular}{|c|c|c|c|c|c|c|c|}
\hline \multirow{2}{*}{ VAS } & \multicolumn{2}{|c|}{$T(n=20)$} & \multicolumn{2}{|c|}{$H(n=17)$} & \multicolumn{2}{|c|}{ TH $(n=23)$} & \multirow[t]{2}{*}{ p-value } \\
\hline & & & & & & & \\
\hline Pre-injection & $7.2 \pm 2.04$ & $\mathrm{~A}^{\dagger}$ & $6.65 \pm 1.77$ & $\mathrm{~A}^{\dagger}$ & $7.34 \pm 2.12$ & $\mathrm{~A}^{\dagger}$ & $0.533^{*}$ \\
\hline After 2 weeks & $4.8 \pm 2.18$ & $\mathrm{~B}^{\dagger}$ & $6.01 \pm 1.46$ & $\mathrm{~A}^{\dagger}$ & $4.82 \pm 1.67$ & $\mathrm{~B}^{\dagger}$ & $0.075^{*}$ \\
\hline After 6 weeks & $5.05 \pm 2.01$ & $\mathrm{~B}^{\dagger}$ & $6.05 \pm 1.65$ & $\mathrm{~A}^{\dagger}$ & $4.6 \pm 2.21$ & $\mathrm{BC}^{\dagger}$ & $0.100 *$ \\
\hline \multirow[t]{2}{*}{ After 12 weeks } & $5.5 \pm 1.51$ & $\mathrm{~B}^{\dagger}$ & $5.99 \pm 1.66$ & $\mathrm{~A}^{\dagger}$ & $3.82 \pm 1.95$ & $\mathrm{C}^{\dagger}$ & $<0.001^{*}$ \\
\hline & $A^{*}$ & & $\mathrm{~A}^{*}$ & & $\mathrm{~B}^{*}$ & & \\
\hline p-value ${ }^{\dagger}$ & $<0.001^{\dagger}$ & & $0.089^{\dagger}$ & & $<0.001^{\dagger}$ & & \\
\hline \multicolumn{8}{|l|}{ ODI } \\
\hline Pre-injection & $20.25 \pm 7.49$ & $\mathrm{~A}^{\dagger}$ & $23.06 \pm 8.65$ & $\mathrm{~A}^{\dagger}$ & $21.01 \pm 8.5$ & $\mathrm{~A}^{\dagger}$ & $0.418^{*}$ \\
\hline \multirow[t]{2}{*}{ After 2 weeks } & $15.9 \pm 7.95$ & $\mathrm{BC}^{\dagger}$ & $21.94 \pm 7.89$ & $\mathrm{~A}^{\dagger}$ & $16.01 \pm 7.8$ & $\mathrm{~B}^{\dagger}$ & $0.015^{*}$ \\
\hline & $\mathrm{A}^{*}$ & & $\mathrm{~B}^{*}$ & & $\mathrm{~A}^{*}$ & & \\
\hline \multirow[t]{2}{*}{ After 6 weeks } & $14.8 \pm 6.45$ & $\mathrm{C}^{\dagger}$ & $20.69 \pm 8.11$ & $\mathrm{~A}^{\dagger}$ & $15.57 \pm 8.64$ & $\mathrm{~B}^{\dagger}$ & 0.019 * \\
\hline & $A^{*}$ & & $\mathrm{~B}^{*}$ & & $\mathrm{~A}^{*}$ & & \\
\hline \multirow[t]{2}{*}{ After 12 weeks } & $17.95 \pm 6.18$ & $\mathrm{AB}^{\dagger}$ & $21.63 \pm 8.43$ & $\mathrm{~A}^{\dagger}$ & $12.35 \pm 7.66$ & $\mathrm{C}^{\dagger}$ & $<0.001^{*}$ \\
\hline & $A^{*}$ & & $\mathrm{~A}^{*}$ & & $\mathrm{~B}^{*}$ & & \\
\hline p-value ${ }^{\dagger}$ & $<0.001^{\dagger}$ & & $0.098^{\dagger}$ & & $<0.001^{\dagger}$ & & \\
\hline
\end{tabular}

Values are mean \pm standard deviation

VAS: Visual analog scale, ODI: Oswestry disability index, T: Triamcinolone, bupivacaine group, H: Hyaluronidase, bupivacaine group, TH: Triamcinolone, hyaluronidase, bupivacaine group

${ }^{*}$ One-way ANOVA, ${ }^{\dagger}$ Repeated measures ANOVA, ABC: Post-hoc test grouping by Tukey-Kramer 
Sang Beom Kim, et al.

Table 3. Comparison of the Mean Decrease of VAS and ODI among Group T, Group H, Group TH

\begin{tabular}{|c|c|c|c|c|c|c|c|}
\hline \multirow{2}{*}{ Mean reduction of VAS } & \multicolumn{2}{|c|}{$T(n=20)$} & \multicolumn{2}{|c|}{$H(n=17)$} & \multicolumn{2}{|c|}{ TH $(n=23)$} & \multirow[t]{2}{*}{ p-value* } \\
\hline & & & & & & & \\
\hline \multirow[t]{2}{*}{ After 2 weeks } & -2.0 & $\mathrm{~A}^{\dagger}$ & -1.0 & $\mathrm{~A}^{\dagger}$ & -3.0 & $\mathrm{~A}^{\dagger}$ & $<0.001^{*}$ \\
\hline & $A^{*}$ & & $\mathrm{~B}^{*}$ & & $A^{*}$ & & \\
\hline \multirow[t]{2}{*}{ After 6 weeks } & -2.0 & $\mathrm{~A}^{\dagger}$ & -1.0 & $\mathrm{~A}^{\dagger}$ & -3.0 & $\mathrm{~A}^{\dagger}$ & $<0.001^{*}$ \\
\hline & $A^{*}$ & & $\mathrm{~B}^{*}$ & & $A^{*}$ & & \\
\hline \multirow[t]{2}{*}{ After 12 weeks } & -2.0 & $\mathrm{~A}^{\dagger}$ & -0.2 & $\mathrm{~A}^{\dagger}$ & -4.0 & $\mathrm{~B}^{\dagger}$ & $<0.001^{*}$ \\
\hline & $\mathrm{A}^{*}$ & & $\mathrm{~B}^{*}$ & & $\mathrm{C}^{*}$ & & \\
\hline p-value ${ }^{\dagger}$ & $0.241^{\dagger}$ & & 0.063 & & 0.002 & & \\
\hline \multicolumn{8}{|c|}{ Mean reduction of ODI } \\
\hline \multirow[t]{2}{*}{ After 2 weeks } & -4.0 & $\mathrm{AB}^{\dagger}$ & -1.0 & $\mathrm{~A}^{\dagger}$ & -5.0 & $\mathrm{~A}^{\dagger}$ & $0.005^{*}$ \\
\hline & $A^{*}$ & & $\mathrm{~B}^{*}$ & & $A^{*}$ & & \\
\hline \multirow[t]{2}{*}{ After 6 weeks } & -5.0 & $\mathrm{~B}^{\dagger}$ & -2.0 & $\mathrm{~A}^{\dagger}$ & -6.0 & $\mathrm{~A}^{\dagger}$ & $0.042^{*}$ \\
\hline & $A^{*}$ & & $\mathrm{~B}^{*}$ & & $A^{*}$ & & \\
\hline \multirow[t]{2}{*}{ After 12 weeks } & -1.6 & $\mathrm{~A}^{\dagger}$ & -1.0 & $\mathrm{~A}^{\dagger}$ & -8.2 & $\mathrm{~B}^{\dagger}$ & $<0.001^{*}$ \\
\hline & $\mathrm{A}^{*}$ & & $\mathrm{~A}^{*}$ & & $\mathrm{~B}^{*}$ & & \\
\hline p-value ${ }^{\dagger}$ & $0.007^{\dagger}$ & & 0.219 & & $<0.001$ & & \\
\hline
\end{tabular}

Values are mean

VAS: Visual analog scale, ODI: Oswestry disability index, T: Triamcinolone, bupivacaine group, H: Hyaluronidase, bupivacaine group, TH: Triamcinolone, hyaluronidase, bupivacaine group

${ }^{*}$ One-way ANOVA, ${ }^{\dagger}$ Repeated measures ANOVA, ABC: Post-hoc test grouping by Tukey-Kramer

Table 4. Pain Relief $>50 \%$ as Measured by Visual Analogue Scale

\begin{tabular}{lccc}
\hline & T & H & TH \\
\hline At 6 weeks & $5 / 20(25.0 \%)$ & $1 / 17(5.9 \%)$ & $10(43.5 \%)$ \\
At 12 weeks & 0 & 0 & $12(52.2 \%)$ \\
\hline
\end{tabular}

T: Triamcinolone, bupivacaine group, H: Hyaluronidase, bupivacaine group, TH: Triamcinolone, hyaluronidase, bupivacaine group

lieving pain in the long term, the ratios of patients that showed at least a $50 \%$ reduction in pain at 6 and 12 weeks after the procedure based on VAS values were calculated by group. At 6 weeks after the procedure, $25.0 \%$ of group $\mathrm{T}, 5.9 \%$ of group $\mathrm{H}$ and $43.5 \%$ of group $\mathrm{TH}$ showed $50 \%$ or more reductions in pain. At 12 weeks after the procedure, $52.2 \%$ of group TH showed $50 \%$ or more reductions in pain but no patients in group $\mathrm{T}$ or group $\mathrm{H}$ answered that their pain decreased by $50 \%$ or more (Table 4 ).

\section{DISCUSSION}

Surgeons have studied diverse materials that can minimize or prevent scar tissues in order to prevent failed back surgery syndromes. Silastic, dacrom, methacrylate, bone graft, synthetic membranes and foams, fat graft, elastase and sodium hyaluronate are examples of those materials. Although these materials were thought to cover regions between the dura mater and nerve roots when the surgery had been completed thereby suppressing the movements of fibroblasts, most study results were negative. ${ }^{14}$ Currently, the fundamentally complete prevention of postoperative scar tissues is not possible although there might be differences in their quantities and thus the generation of scars around surgery sites is unavoidable.

Scar tissue is generated following surgery. Scar tissue exists at surgery sites even when they do not directly act to trigger pain and may obstruct the progress of drugs when injection therapy is conducted in the vicinity of the surgery sites later. ${ }^{9}$ By the given the definition of FBSS and their causal factors stated in Introduction, FBSS as defined above, can be caused by pain triggered by eminent scar tissue or recurrent due to other lesions that require treatment injections near the surgical site. It is thought that it is believed that the addition of therapeutic agents, such as hyaluonidase ${ }^{10}$ which suppresses fibroplasia and remove barriers between tissues, would treat 
scars or help drug progress.

Therefore in the special situation of 'after a spinal surgery', this study was intended to examine the independent effect or supplementary effect of hyaluronidase to maximize the effects of steroid and other drugs in cases where epidural steroid injections are used that can be considered as a therapeutic approach.

Factors that trigger pain in patients that complain about low back pain or lower extremity radiating pain may include nerve root compression, mechanical irritation and inflammation. ${ }^{15,16}$ When inflammation begins, peripheral vasodilation, edema, fibrin deposition, white blood cell agglutination, phagocytosis , etc. are involved in inflammation. During the latter period of inflammation, peripheral vascular proliferation, fibroblast proliferation, collagen deposition and scar formation occur. After undergoing these inflammation processes, nerve roots show increased $\mathrm{Na}^{+}$channel expression and mechanical sensitivity. In addition, increased cytokine expression makes the nerve roots very sensitive to pressure by sensitization. Therefore, nerve roots start to become OR become continuously and easily excited by even a very weak stimulus. ${ }^{17,18}$ Through these mechanisms, the fibrin generated by FBSS is around nerve roots causes damage and compression of the nerve roots and suppresses the mobility of the nerve roots thereby causing chronic pain. ${ }^{7,8}$ Therefore, a steroid is effective in relieving initial pain in radiculopathy but not so as effective in cases where fibroblast proliferation, collagen deposition, and scar formation around the nerve root during the latter period of the inflammatory process. ${ }^{19}$

According to a study by Ross et al., ${ }^{14}$ epidural scars are very closely related with radiating pain. And every time a scar size increases by $25 \%$, the risk of radiating pain will double. If there are extensive epidural scars, the risk of radiating pain will be around 3.2 times higher. As these effects of scar tissues were discovered, hyaluronidase has been gaining increasing attention as a FBSS treatment due to its involvement in the suppression and decomposition of fibroplasias of tissues and the promotion of drug diffusion.

Hyaluronidase is an enzyme that is secreted from the intestine of mammals. Hyaluronidase hydrolyze glucosaminic bonds between hyaluronic acid and connective tissues, removes barriers between tissues to change the permeability of the connective tissues and reduces viscosity between cells as well as reduces fibrous tissue proliferation. ${ }^{10}$ With these actions, hyaluronidase reduces swelling and edema in tissues and increases drug penetration into tissues in various injection procedures and thus it is widely used in many areas.

In this study, both group $\mathrm{T}$ and group $\mathrm{TH}$ showed significant decreases in pain and inconvenience in activities of daily living by six weeks after the procedure. However, when 12 weeks had passed, unlike group T, group TH was administered both hyaluronidase and steroids showed statistically significant continuous pain relief and functional improvement. That is, the degrees of pain relief similar to those of group TH were observed in group $\mathrm{T}$ in the early stage after the procedure because of the inflammation suppressing the effect of the steroid. But as time passed, superior pain relief was observed in group TH compared to group $\mathrm{T}$ and superior results were also observed in group TH in pain relief period and in subjective senses of inconvenience. At all time points, group TH showed best results among the three groups. On the other hand, group $\mathrm{H}$ showed no statistically significant pain relief or functional improvement at any of the time points; 2, 6 , and 12 weeks after the procedure when compared with those before the procedure. This results are considered to have been shown because, although few effects can be expected when hyaluronidase has been used independently, if it is administered together with a steroid, it will bring about synergy effects for pain relief by helping the penetration of the steroid with its unique actions of suppressing fibroplasias, collagen deposition and scar formation. A previous study was conducted by Kim et al. ${ }^{20}$ that examined the added effects of hyaluronidase on patients with herniation of lumbar intervertebral disc. The previous study showed that the additional effect of hyaluronidase only in ODI at 8 weeks after the procedure. But this study showed the effects of hyaluronidase on FBSS patients. The drug continuously showed significant effects on both VAS and ODI until 12 weeks after the procedure. As a result, it was considered that the application of hyaluronidase might be more effective on failed back surgery syndrome patients involving fibroplasia than on simple inflammatory reactions. Although it was not a study focused on the independent effects of hyaluronidase, a study ${ }^{21}$ reported to compare a group of FBSS patients administered with steroid and hypertonic saline with a group that was administered hyaluronidase, steroid and hypertonic saline. In this study, the 
group administered with hyaluronidase and other drugs showed long-term pain relief effects. These results had supported the fact identified in this study: that although hyaluronidase cannot independently demonstrate pain relieving effects in FBSS patients, it can show added effects when used together with other drugs such as steroids.

To treat failed back surgery syndromes, it is important to remove or treat the fundamental causes that trigger the recurrence of pain along with diverse causes. Among diverse treatments of epidural scars, adhesiolysis was a recently common treatment, unlike the simple epidural injections used in this study. According to the studies, adhesiolysis is more effective than epidural steroid injections added with hyaluronidase and hypertonic saline. ${ }^{4}$ Adhesiolysis aims to detach the dura mater and nerve roots mechanically from fibrous tissues such as membranes or bands in order to discharge inflammatory effusion, decompress epidural spaces and help the accurate transmission of drugs. ${ }^{22}$ Adhesiolysis may be conducted in an endoscopic method or a non-endoscopic method. The endoscopic method is advantageous in that we can easily find and dissolve the fibrosis and adhesion of nerve root lesion which is not identified in MRI. ${ }^{23}$ The non-endoscopic adhesiolysis dissolves the adhesion by having a spiral soft Racz epidural catheter made of stainless steel and coated with Teflon to pass through an adhesion or scar regions. Although adhesiolysis is more effective in treatment than epidural injections, ${ }^{4}$ spinal endoscopic procedures are more invasive because of the insertion of the endoscopic expander. In non-endoscopic procedures, drugs are additionally injected two more times at 24 hours after the first procedure for effective treatment in some cases. An infection, such as epidural abscess, sometimes occurs ${ }^{24}$ due to invasive and repetitive characteristics of this procedure. According to a report by Perkins et al., ${ }^{25}$ there were cases of a broken adhesiolysis catheter that made a new radiculopathy and thus an operation was performed. Considering these factors, there are opinions that the patients should be first treated with epidural injections and endoscopic or nonendoscopic epidural adhesiolysis should be considered when epidural injection failed. ${ }^{22}$

Limitations of this study may include the fact that internal disc disruption was not screened when study subjects were diagnosed and selected and the fact that patients' psychiatric or psychological problems ${ }^{4}$ that acted as consider giving an example could not be excluded. In addition, since the study was conducted mainly in an out-patient department, control of the types of surgeries and surgeons could not be controlled and patient' electrodiagnositc, and radiologic information could not be sufficiently prepared. The time taken to visit the hospital after surgeries was too long. So it is possible that other diseases such as spinal stenosis and the herniation of intervertebral disc may accompany. Consequently it is difficult to study pure FBSS patients who have only fibrous tissue problem. Diverse injection methods for failed back surgery syndromes could not be accessed. In this study, the dose of hyaluronidase was only $1500 \mathrm{IU}$, therefore additional studies should be necessary on the dose that may produce maximum effects.

\section{CONCLUSION}

Failed back surgery syndrome patients were divided into three groups; a group that was administered a combination of triamcinolone and a local anesthetic (group $\mathrm{T}$ ), a group that was administered a combination of a local anesthetic and hyaluronidase (group $\mathrm{H}$ ) and a group that was administered asteroid, a local anesthetic and hyaluronidase (group $\mathrm{TH}$ ) for this randomized controlled study. In decrements VAS and ODI after the procedure, group TH showed the largest effects among the three groups at all time points.

Therefore, in the case of failed back surgery syndrome patients, interlaminar lumbar epidural injections with a mixture of hyaluronidase and steroid is expected to be more efficient in reducing pain and the sense of inconvenience than steroid or hyaluronidase single therapy.

\section{ACKNOWLEDGEMENTS}

This study was supported by research funds from DongA University.

\section{REFERENCES}

1. Wahlgren DR, Atkinson JH, Epping-Jordan JE, Williams RA, Pruitt SD, Klapow JC, Patterson TL, Grant I, Webster JS, Slater MA. One-year follow-up of first onset low back pain. Pain 1997; 73: 213-221

2. Katz JN. Lumbar spinal fusion. Surgical rates, costs, and complications. Spine 1995; 20: 78S-83S 
3. Yang HS, Lee SH, Ryu CH, Lee JY, Bae JH. Correlation of the clinical factors and gait parameters in failed back surgery syndrome. J Korean Acad Rehab Med 2004; 28: 371-378

4. Epter RS, Helm S 2nd, Hayek SM, Benyamin RM, Smith HS, Abdi S. Systemic review of percutaneous adhesiolysis and management of chronic low back pain in post lumbar surgery syndrome. Pain Physician 2009; 12: 361-378

5. Yamagami H, Hashizume K, Sha K, Furuya H, Okuda T. Evaluation of selective lumbar radiculography and radicular block. Masui 1994; 43: 253-257

6. Mooij JJ. Spinal arachnoiditis: disease or coincidence? Acta Neurochir 1980; 53: 151-160

7. Winnie AP, Hartman JT, Meyers HL Jr, Ramamurthy S, Barangan V. Pain clinic. II. Intradural and extradural corticosteroids for sciatica. Anesth Analg 1972; 51: 990-1003

8. Pountain GD, Keegan AL, Jayson MI. Impaired fibrinolytic activity in defined chronic back pain syndrome. Spine 1987; 12: 83-86

9. Fredman B, Nun MB, Zohar E, Iraqi G, Shapiro M, Gepstein R, Jedeikin R. Epidural steroids for treating "failed back surgery syndrome": is fluoroscopy really necessary? Anesth Analg 1999; 88: 367-372

10. Menzel EJ, Farr C. Hyaluronidase and its substrate hyaluronan: biochemistry, biological activities and therapeutic uses. Cancer Lett 1998; 131: 3-11

11. Lee KJ, Han SG, Yoon SH, Kim JS, Lee YS. Nerve root block with corticosteroids, hyaluronidase, and local anesthetic in the failed back surgery syndrome. Korean J Pain 1999; 12: 191-194

12. Borg PA, Krijnen HJ. Hyaluronidase in the management of pain due to postlaminectomy scar tissue. Pain 1994; 58: 273-276

13. Devulder J. Transforaminal nerve root sleeve injection with corticosteroids, hyaluronidase, and local anesthetic in the failed back surgery syndrome. J Spinal Disord 1998; 11: 151-154

14. Ross JS, Robertson JT, Frederickson RC, Petrie JL, Obuchowski N, Modic MT, deTribolet N. Association between peridural scar and recurrent radicular pain after lumbar discectomy: magnetic resonance evaluation. ADCON-L European Study Group. Neurosurgery
1996; 38: 855-861

15. Hayashi N, Weinstein JN, Meller ST, Lee HM, Spratt KF, Gebhart GF. The effect of epidural injection of betamethasone or bupivacaine in a rat model of lumbar radiculopathy. Spine 1998; 23: 877-885

16. Olmarker K. Spinal nerve root compression. Nutrition and function of the porcine cauda equina compressed in vivo. Acta Orthop Scand Suppl 1991; 242: 1-27

17. Kallakuri S, Takebayashi T, Ozaktay AC, Chen C, Yang S, Wooley PH, Cavanaugh JM. The effects of epidural application of allografted nucleus pulposus in rats on cytokine expression, limb withdrawal and nerve root discharge. Eur Spine J 2005; 14: 956-964

18. Howe JF, Loeser JD, Calvin WH. Mechanosensitivity of dorsal root ganglia and chronically injured axons: a physiological basis for the radicular pain of nerve root compression. Pain 1977; 3: 25-41

19. Jo DH, Hong JH, Kim MH. The effect of transforaminal epidural block with hyaluronidase and triamcinolone. Korean J Pain 2005; 18: 176-180

20. Kim SB, Lee KW, Lee JH, Kim MA, Kim BH. The additional effect of hyaluronidase in lumbar interlaminar epidural injection. Ann Rehabil Med 2011; 35: 405-411

21. Yousef AA, EL-Deen AS, Al-Deeb AE. The role of adding hyaluronidase to fluoroscopically guided caudal steroid and hypertonic saline injection in patients with failed back surgery syndrome: a prospective, double-blinded, randomized study. Pain Pract 2010; 10: $548-553$

22. Lee SI, Kim KT, Hwang JK. Endoscopic and non-endoscopic epidural adhesiolysis in FBSS patient. Korean J Anesthesiol 2004; 46: 329-335

23. Saitoh K, Igarashi T, Hirabayashi Y, Horikawa Y, Seo N, Motegi R, Miyashita K. Epiduroscopy in patients with chronic low back pain without remarkable findings on magnetic resonance imaging. Masui 2001; 50: 12571259

24. Talu GK, Erdine S. Complications of epidural neuroplasty: a retrospective evaluation. Neuromodulation 2003; 6: 237-347

25. Perkins WJ, Davis DH, Huntoon MA, Horlocker TT. A retained Racz catether fragment after epidural neurolysis: implications during magnetic resonance imaging. Anesth Analg 2003; 96: 1717-1719 